\section{EDUARDO MARTÍNEZ TORNER Y LA JUNTA PARA AMPLIACIÓN DE ESTUDIOS EN ESPAÑA}

\author{
Susana Asensio Llamas \\ CSIC \\ asensio@orgc.csic.es
}

\begin{abstract}
The Asturian musicologist E. M. Torner (Oviedo 1888London 1955) was the first scholar working with music in a Spanish research center of international scope in Europe. The fieldwork materials he collected, investigation, courses given, and outreach activities and collaborations at the Center of Historical Studies (CEH) of the JAE (1910-1939), comprise a large amount of oral literature and music materials. Furthermore, the vast amount of unpublished work, and the ostracism to which he was condemned while living in exile and after his death, until the end of Franco's dictatorship, may show to contemporary researchers that his legacy was much more transcendent than acknowledged -especially during the 1930s- not only in the academic field but at a popular level as well. This article deals with his early approach to the JAE, the research he undertook there, and the outreach activities carried out until his exile in the UK. An exile forced by his strong political support of Spain's Second Republic.
\end{abstract}

KEY WORDS: Torner; Spanish Second Republic; folklore; Center for Historical Studies; musicology.

\section{INTRODUCCIÓN}

Eduardo Martínez Torner nació en Oviedo en 1888 y desde muy joven su afición por la música le llevó a proseguir los estudios de piano en el conservatorio de su ciudad natal'. Termina su carrera examinándose en Madrid en 1910, y en este mismo año comienza el contacto con la Junta para Ampliación de Estudios e Investigaciones Científicas (JAE), la primera institución de carácter netamente científico en España, a través de una carta enviada al Centro de Estudios Históricos (CEH) en la que solicita una beca. Este centro, fundado en 1910 en el seno de la JAE, fue dirigido desde sus inicios hasta su disolución tras la Guerra Civil por Ramón Menéndez Pidal, figura de enorme impacto en la investigación española, y sería a través de él cómo Torner se introduce en la metodología de la filología primero y después desarrolla su propia metodología de recogida y análisis musicológico de las músicas históricas y populares.

\section{EDUARDO MARTÍNEZ TORNER AND THE SPANISH BOARD FOR EXTENSION OF STUDIES}

RESUMEN: El asturiano E. M. Torner (1888-1955) fue el primer musicólogo en integrarse en un organismo de investigación científica de dimensión nacional en España e internacional en Europa. Sus trabajos de recogida, investigaciones, cursos y actividades de divulgación o colaboraciones desde el Centro de Estudios Históricos de la JAE (1910-1939) dejaron una monumental obra de colección y sistematización de materiales musicales y literarios de tradición oral. Asimismo, la gran cantidad de materiales que dejó inéditos, y el ostracismo desarrollado en torno a su figura durante su exilio y posterior muerte, hasta el fin de la dictadura franquista, inducen a pensar a los investigadores que su labor fue mucho más trascendente, especialmente en la década de 1930, tanto a nivel popular como académico. Aqui se relatará su ingreso en la JAE, las investigaciones desarrolladas por él alli, y las actividades de divulgación que llevó a cabo hasta su exilio en Gran Bretaña -exilio debido a sus fuertes lazos políticos con la Segunda República.

PALABRAS CLAVE: Torner; Segunda República; folklore; Centro de Estudios Históricos; musicología.

Muy a menudo se ha citado la estancia de Torner en Paris, entre 1912 y 1914, como el inicio de sus acercamientos científicos a la musicología (González Cobas, 1975, s.f; Mallo, 1980, 1984; Gómez, 1989, 2006, 2009), a través del magisterio de Vincent d'Indy en la Schola Cantorum. Sin embargo, en la carta que envía a Menéndez Pidal el 22 de abril de 1910 ya avanza sus rigurosas ideas sobre la recogida de músicas populares, ideas que luego plasmará en su cancionero asturiano de 1920: una transcripción de la melodía exacta, sin arreglos de melodías ni ritmos; la recogida de variantes como elemento comparativo imprescindible; y la notación de toda la información relativa al lugar, fecha, intérpretes, etc. Todo ello para "formar una colección de música popular que responda al interés científico y a las exigencias de los estudios folklóricos modernos", según comenta textualmente ${ }^{2}$. La beca, sin embargo, no le es concedida en esta ocasión. 
La progresiva integración de Torner en el CEH en la segunda década del siglo XX, en el corazón de la investigación española en humanidades, entonces aún por desarrollar, moldea sus intereses, temas de investigación, colaboraciones y producción científica hasta su exilio en 1939. Pero su colaboración constante con otras instituciones y colegas, a lo largo de sus veinte años de relación con la JAE (1910-1939), definen también un espíritu ecléctico, de gustos e influencias variadas, no adscrito a una sola corriente de pensamiento -aunque en la época la intelectualidad solía dividirse en función de estas adscripciones-. Como se verá en las páginas siguientes, esta modernidad aparece no sólo en referencia a los temas de investigación que trata, sino también en la puesta en práctica de sus ideas sobre la divulgación "popular" de la investigación musical. Estas ideas, así como su concepción de la "importancia histórica de lo popular", le llevan a ser un elemento incómodo dentro de la academia y de la investigación tras el golpe de estado de 1936. Su circulación constante en las fronteras disciplinares, sus modernas metodologías, su implicación personal en la divulgación de la investigación sobre música popular y, sobre todo, su demostrada adscripción y apoyo al gobierno de la Segunda República, le fuerzan a un exilio del que ya no volverá.

Con el inicio de la Guerra Civil, Torner se desplaza de Madrid a Valencia, y luego a Barcelona, para salir desde allí hacia Francia en 1939, donde pasa unos meses en el campo de internamiento de Argelès-sur-Mer antes de comenzar su exilio londinense. Muere en Londres en 1955, algunos años después de haber llevado allí a parte de su familia ${ }^{3}$. En los quince años de exilio, a falta de materiales, colegas e instituciones donde desarrollar más cómodamente su investigación, Torner se reinventa a sí mismo, retoma sus intereses filológicos y rítmicos, así como nuevos trabajos de edición de músicas, lejos de España pero sin olvidarla nunca. A su muerte deja dos tratados monumentales e inéditos, Lírica Hispánica y Rítmica Hispánica, que son la mejor constancia de su trabajo en el exilio.

\section{Los estudios musicológicos en el Centro DE Estudios Históricos}

La dirección del CEH por Menéndez Pidal durante toda su historia (1910-1939) consolida la filología como disciplina preferencial, y núcleo duro de la investigación desde los primeros años en el Centro. Por esta razón Torner se integra en la sección creada para ella, junto con otros estudiosos que provenían principalmente de la filología y la historia.

En estas primeras décadas del siglo XX los grandes cambios que afectan a toda la filología a nivel europeo, y en especial desde sus dos grandes centros, Alemania y Francia, se han filtrado ya a la academia española. Las nuevas tendencias tienden a eliminar la influencia anterior de las escuelas de los neogramáticos, que han perdido protagonismo por la falta de demostración de sus teorías, de carácter autorreferencial, desconectadas de los espacios culturales en los que tienen lugar. López Sánchez resume breve pero eficazmente el paso a esta nueva concepción de la filología como disciplina científica:

"A través de la conexión del hecho lingüístico con el espacio donde habia tenido lugar adquirió la hasta entonces aislada observación lingüistica un fundamento en una realidad exterior a lo lingüístico [...]. La atención se desvió hacia factores externos de naturaleza geográfica o histórica. Este fue el fenómeno revolucionario en la lingüística de finales del siglo XIX, pero, a cambio, la geografía lingüística pagó un precio, ya que permaneció apegada al elemento fonético de la lengua y descuidó su contenido, y el sentido de sus componentes. Tan sólo en una etapa posterior, en la que se presta atención al folklore, se llevó a cabo la definitiva transformación de la investigación dialectal en una búsqueda de problemas de contenido" (López Sánchez, 2006, 258).

En este contexto disciplinar se integra Torner en el $\mathrm{CEH}_{1}$ aportando su experiencia en las recogidas de textos $y$ músicas de tradición oral, y sus estudios sobre el folklore como temas centrales de su investigación, y adoptando las metodologías pidalianas en su posterior análisis y contextualización. Aunque en España la atención que se ha prestado al folklore no ha provenido frecuentemente de la academia ni de los centros de investigación, el esfuerzo de Torner en este sentido, sigue siendo un precedente a reivindicar.

Menéndez Pidal compone en el CEH un grupo de trabajo formado con alumnos procedentes de la Universidad Central, donde ya impartía entonces sus clases, y otros colaboradores de diferente procedencia ${ }^{4}$. Este grupo comienza a trabajar alrededor del tema "Orígenes de la Lengua Española" y pronto pasa a ser la Sección de Filología, la más 


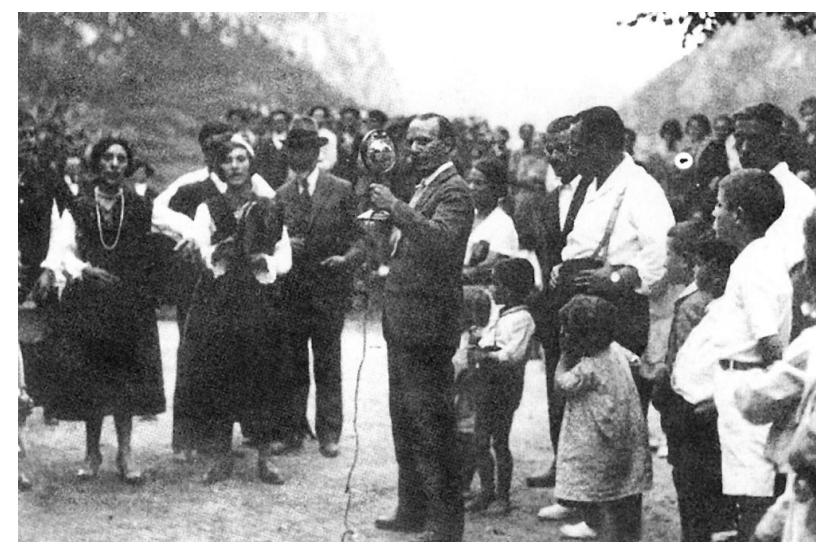

Figura 1. Torner experimenta las nuevas tecnologías de grabación en Arenas de Cabrales, Asturias, acompañado de Ramón Menéndez Pidal y Kurt Schindler (21 de agosto de 1932). Fondo Schindler, Hispanic Society of America, Nueva York (reproducida en Catalán, 2001, IV-xxxvii)

nutrida del Centro, en la que Torner aportaría sus trabajos y conocimientos al servicio de un empeño común. En unos pocos años, y gracias al extraordinario trabajo en equipo que logró su liderazgo, Menéndez Pidal sitúa también al CEH y a España en la filología europea, demostrando el carácter panhispánico del romancero y desterrando aproximaciones parciales y regionalistas, o la consideración de mero apéndice de la tradición oral de los siglos XIX y $X X$, como aún proponía Foulché-Delbosc (Menéndez Pidal, 1910; Catalán, 2001, tomo I, 58) 5 .

La publicación en la que el filólogo enuncia por primera vez sus grandes teorías sobre el origen y la pervivencia del romancero pan-hispánico aparece en 1910, y recoge las conferencias que el filólogo había dado en Nueva York un año antes. Éstas expresan ideas entonces revolucionarias, como que "la tradición antigua (escrita) del Romancero es inseparable de la moderna", que "los romances populares siguieron propagándose por medio de la tradición oral", o que "la música es una poderosa fuerza vital del Romancero, [...] como las alas que le llevan a través del tiempo y del espacio, pues al par que ella brota insistente en la memoria [...] ayuda a recordar más fácilmente los versos por ella animados" (Menéndez Pidal, 1910, 85). Y continúa:

"Asi el Romancero durante los siglos XV, XVI y XVII, al mismo tiempo que se difundía en la literatura, divorciado de la música, halló, unido a ella, en la memoria popular un firme arraigo, y transmitido de generación en generación logró una expansión territorial que parece fabulosa" (Menéndez Pidal, 1910, 85-86).

De esta manera, las músicas populares vehiculan un tipo de literatura oral que se mantuvo desde el siglo XV en el imaginario de muchas zonas, al menos hasta el mismo final del siglo XX -y en especial en la zona del noroeste peninsular-. Pidal había llegado a esta conclusión tras haber recolectado muchas versiones romancísticas que le llegaban con melodia, aunque él no pudiera recogerla, y tras haber sido informado de otras tantas por los recolectores que le enviaban materiales desde toda la geografía peninsular $-y$ más tarde, también insular y ultramarina.

No fue casual, pues, que la música estuviese recogida en sus conferencias, texto de referencia absoluto para comprender la labor desarrollada luego en el Centro, y para entender la trascendencia de la escuela pidaliana. En 1910, llegada su colección personal a superar los 1.500 items recolectados de diversas formas, la música ya formaba parte de sus preocupaciones. Se tiene constancia de que Torner acompañó algunas de sus conferencias al piano con otros intérpretes ${ }^{6}$.

Unos años antes de que el CEH fuera una realidad, Menéndez Pidal había comenzado a trabajar en conexión con especialistas en música muy relevantes, como Felipe Pedrell y Manuel Manrique de Lara, por recomendación, entre otros, de José Benoliel ${ }^{7}$. En efecto, en 1904 y tras encontrar varias melodías muy interesantes entre los judeo-españoles de Tánger y Tetuán, Benoliel le sugiere a Pidal, en una carta del 14 de junio, recoger las músicas y hacer con ellas un estudio "sobre composiciones musicales de 4 ó 5 siglos a esta parte" (Catalán, 2001, 37).

Poco antes, entre 1900 y 1902, Pedrell había transcrito melodías para Pidal, y desde 1904 es Manrique de Lara e colaborador más asiduo, y su más destacado recolector, especialmente entre las comunidades sefardies. A partir de 1905 trabajan juntos en varias ocasiones anotando textos, músicas y datos relevantes en recogidas conjuntas, como la que realizan a las Navas del Marqués, Ávila (Catalán, 2001, 41-42, 45-46). De hecho, es gracias a Manrique de Lara y a su colaboración con Menéndez Pidal que el aspecto musical comienza a cobrar especial relieve en la colección general del romancero. 
El ideario pidaliano del romancero es trasvasado así, sutilmente, como por fertilización natural, desde los estudios filológicos a los estudios musicales, y las pervivencias formulaicas que buscan los filólogos son sustituidas por la curiosidad modal o rítmica de músicos y musicólogos ${ }^{8}$. A pesar de que los inicios y el contexto fueron entonces favorables, no se creó, sin embargo, un grupo significante de musicólogos alrededor del núcleo filológico. Más bien éstos parecian colaborar en proyectos puntuales al servicio de los intereses y prioridades de la Sección de Filología.

Manrique de Lara compartió con Martínez Torner, y con otros estudiosos relacionados con el CEH, como Ribera, Castro Escudero o Bal y Gay, intereses no sólo musicales, sino también musicológicos:

"El interés de Manrique de Lara por la música antigua y por lo que en aquellos tiempos aún constituia un problema difícil de resolver, el de interpretar en su forma debida los sistemas de notación empleados por los vihuelistas en los libros de música de los siglos XV, XVI, y XVII, le hizo planear el 'completar' sus investigaciones de campo peninsulares" (Catalán, 2001, 55).

Su carrera se desarrolla, sin embargo, entre el ejército y la composición y, aunque llegó a disfrutar de varias pensiones de la Junta, no hay constancia de que mantuviese ningún tipo de contacto con el resto de músicos y musicólogos reunidos alrededor de la Residencia de Estudiantes y el $\mathrm{CEH}^{9}$.

A pesar del interés común, sólo Martínez Torner y Bal y Gay trabajan finalmente en la transcripción de los repertorios vihuelísticos (Torner, 1923b; Bal y Gay, 1939b) ${ }^{10}$. Y aunque casi todos realizan trabajo de campo, acompañados o dirigidos por Menéndez Pidal o Tomás Navarro Tomás, en muy contadas ocasiones trabajan juntos -la colaboración de Martínez Torner con Bal y Gay en el Cancionero Gallego es una excepción en este sentido ${ }^{11}$, así como las colaboraciones esporádicas con Castro Escudero ${ }^{12}$-. Quizá fuera esta atomización, y la posterior división de tareas -Manrique recolector, Torner musicólogo dedicado al romancero, y Bal y Gay dedicado a los repertorios históricos- la que sentenciaría prematuramente el desarrollo de la investigación musicológica concebida de una manera sistemática y multidisciplinar en la Junta ${ }^{13}$.
Julián Ribera, arabista interesado por la música, se desvincularía del Centro junto con Miguel Asín Palacios en 1916, desarrollando toda su carrera posterior en Aragón, y publicando sus estudios musicales sobre las Cantigas de Alfonso $X_{1}$ la métrica gallega, la música árabe y la jota, en los años veinte $(1922,1925,1927,1928)$, completamente al margen del CEH. Algunas de sus teorias en cuanto a la transcripción musical serán seguidas por Torner y provocarán su distanciamiento de otros colegas, como Bal y Gay, y estudiosos, como Anglès.

El resultado final es que no existe una colaboración sostenida entre los diferentes investigadores para avanzar en los logros y conocimientos musicológicos de manera conjunta. Con la desintegración del CEH tras la Guerra Civil, se forma un nuevo y muy diferente núcleo musicológico en el seno del Consejo Superior de Investigaciones Científicas, en adelante CSIC. Será a partir de 1943, en torno a la figura de Higinio Anglès. En este nuevo Instituto Español de Musicología, las músicas populares ya sólo tendrán relevancia en cuanto a elementos auxiliares de la musicología histórica más decimonónica, de manera que la trabajosa relación establecida entre los estudios filológicos y musicológicos será sesgada tempranamente, y nunca retomada institucionalmente en el CSIC.

A pesar de su variedad y diferencias, todos los investigadores del CEH comparten entonces la convicción de que las tradiciones populares muestran las supervivencias de tiempos incluso anteriores a las recogidas en las fuentes cultas. Sus intereses musicológicos son ya, por tanto, híbridos, divididos entre las tradiciones orales que recogen y transcriben in situ, y las fuentes escritas conocidas de los siglos XIII al XVIII. La demostración de que sus intuiciones son correctas, y ambos repertorios están conectados, viene de la mano de la filología, pero permea rápidamente a los musicólogos. La ruptura de la guerra retrasa sus logros, anclando la disciplina del folklore en un lugar vicario respecto a las fuentes históricas, y lastrando más tarde las investigaciones, que entonces eran pioneras, hasta convertirlas en meras anécdotas sin relevancia académica en España ${ }^{14}$.

La incorporación de Torner a esta Sección de Filología es progresiva y probablemente fruto de muchas conexiones y encuentros casuales. Torner envía su primera carta de petición de pensión, que entonces no le es concedida ${ }^{15}$, en abril de 1910, como se ha comentado. Además de la 
escasez de medios y la avalancha de solicitudes provocada porque la JAE volvía a tener el control sobre las pensiones que había perdido en $1907^{16}$, hay otras razones que pueden haber influido en la no concesión.

Una pudo ser que en aquellos momentos Menéndez Pidal ya estaba trabajando en colaboración con Manrique de Lara de manera estable, como se ha visto, y es probable que tuviera cubiertas sus "necesidades musicales" más perentorias. Lo más probable, sin embargo, es que en primavera Menéndez Pidal ya tuviese preparado el viaje que haría en el verano de 1910 con otros dialectólogos a León y Asturias (Catalán, 2001, 62-64), y que la petición de Torner, centrada en aquellos momentos en Asturias, no resultase de interés para el desarrollo de la recién creada sección. Los progresivos acercamientos disciplinarios de uno y otro -de Pidal al Folklore, y de Torner a la Filología- darán como resultado la vinculación formal de Torner al proyecto conjunto del romancero, primero español y luego pan-hispánico.

De todas maneras, lo cierto es que la mayor parte de las pensiones concedidas en relación con la música, estaban destinadas a maestros, con el objetivo de mejorar sus competencias en educación musical, formarlos mediante clases en el extranjero, y que luego ellos pusiesen en práctica los conocimientos adquiridos a su vuelta a España (Sánchez de Andrés, 2006, 235). También a músicos profesionales, principalmente compositores e intérpretes (2006, 238-242). Dentro de este último grupo, y en franca minoría, estaban aquellos profesionales destinados a la investigación musicológica en alguna de sus facetas, como Torner, Bal y Gay o Manrique de Lara.

Cuando Torner vuelve en 1914 a España, tras su estancia parisina, trae consigo todo un bagaje proveniente de la musicología sistemática alemana y francesa, por lo que encuentra poco o nulo eco intelectual en sus empeños ${ }^{17}$. Aunque nuevas en nuestro país, estas corrientes no representan a la modernidad, sino a la tradición -a la valorización de la tradición concretamente-. Torner se convierte en un moderno intelectual de la tradición, pero eso ya no es moderno en España, cuyas vanguardias se dirigen más a la invención de nuevas identidades representativas que en la valoración de las antiguas.

Por eso, aunque parte de los intereses que desarrolla Torner en torno a los repertorios populares de tradición oral en

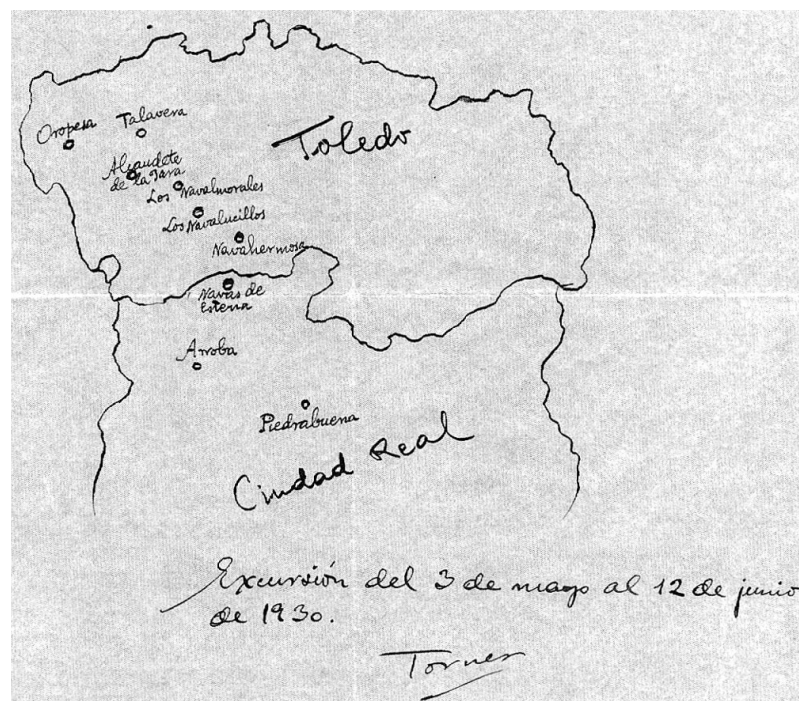

Figura 2. Mapa realizado por Torner de la salida de campo a Toledo y Ciudad Real del 3 de mayo al 12 de junio de 1930. Archivo Menéndez-Pidal/Goyri, Madrid

general y los romances en particular fueron compartidos con otros colegas, su postura estética era claramente distante de la que abanderaban el Grupo de los Ocho en la Residencia de Estudiantes, o Adolfo Salazar desde su espacio de crítica musical en el periódico El Sol. Por un lado la musicología de la música popular bebe en esta época de las fuentes metodológicas de la filología, en pleno proceso de cambio y autodefinición, y por otro, se divorcia de la música práctica en boga en aquel momento, representada por las vanguardias y en donde la tradición no significaba más que un toque pintoresco o un paso hacia atrás. Aunque en este artículo no se hable de la labor compositiva de Torner, es relevante destacar que sus piezas más relevantes y difundidas en Madrid fueron el poema sinfónico Fiesta en la Aldea, compuesto para el "Orfeón de Mieres", y dos zarzuelas, La Promesa, estrenada en 1928, y La Maragata, estrenada en $1931^{18}$.

El hecho de que Torner no hubiese recibido su educación musical formal en el ámbito eclesial, como era tan frecuente entonces, también fue un factor de diferenciación con respecto a otros colegas musicólogos sacerdotes 0 ex-seminaristas. La soledad del camino emprendido por Torner es, por tanto, total en sus inicios ${ }^{19}$. A pesar de ello, su modernidad reside, entonces como ahora, en el reconocimiento del pasado con la vista en el futuro, y en su 
aproximación metodológicamente innovadora al análisis y la clasificación de los repertorios populares.

La novedad que aportó Torner fue de método y de objetivos. Como músico, el hecho de que apoyase su producción compositiva en el folklore español -tan común entonces en España- no era nuevo ni moderno, y esto lastró enormemente su consideración profesional. Como intelectual, ese conocimiento de la tradición fue el que le permitió la entrada en el $\mathrm{CEH}$, paradójicamente, y el que le permitió trabajar directamente con Menéndez Pidal y adquirir las herramientas metodológicas necesarias.

El interés de Torner se irá desplazando a lo largo de toda su carrera profesional del interés musicológico, expresado en la compilación y análisis de músicas populares, al interés histórico y filológico, expresado en las publicaciones del Centro y la Residencia, y pedagógico, especialmente después de sus experiencias al frente del Coro de las Misiones Pedagógicas entre 1931 y 1936. A lo largo del tiempo, y de todos sus desplazamientos, mantendrá sin embargo, como decía Homero Seris, una "perfecta armonía entre el erudito y el artista" (1966, 11).

\section{TORNER Y LA INVESTIGACIÓN MUSICOLÓGICA}

Torner comienza la recogida esporádica de músicas y textos de tradición oral ya antes de su viaje a París y antes de su estancia en Madrid, pero es en el CEH madrileño donde comienza la sistematización de sus análisis y conclusiones. Las Memorias de la JAE dan cuenta sólo de algunas de las actividades de Torner en el $\mathrm{CEH}$, siendo mencionado en relación con sus colaboraciones para la Sección de Filología ${ }^{20}$, con los cursos de vacaciones para extranjeros ${ }^{21}$, con la dirección de la misión folklórico-musical ${ }^{22}$, y con su trabajo para la Comisión de Estudios en Galicia ${ }^{23}$.

Entre 1910 y 1916 Torner se vincula de diferentes maneras a la Institución Libre de Enseñanza, a la Residencia de Estudiantes, y al CEH, pero esta vinculación no se convierte en formal hasta 1916, con la creación de la Sub-sección de Folklore dentro del Centro ${ }^{24}$. En 1934, la dirección de los trabajos folklóricos del archivo ya había juntado 1.142 discos catalogados, que provenían de los siguientes conceptos: "adquiridos en el mercado, 938; recogidos por el doctor Schindler, 175; editados por el Archivo de la Palabra, 29"25.

En una carta de solicitud de pensión, que tampoco le fue concedida, fechada el 26 de febrero de $1919^{26}$ aparecen, en el apartado de la "Justificación de la Instancia", los trabajos que Torner habia hecho para la JAE narrados por él en tercera persona. Relata las pensiones concedidas para recoger romances en León y Asturias en 1916, y en el alto Aragón en 1917, y también los trabajos desarrollados para el CEH:

"Ha trabajado durante los cursos de 1915-1916, 1916-1917, 1917-1918, y continúa en el curso actual [1919] en el Centro de Estudios Históricos, bajo la dirección de D. Ramón Menéndez Pidal, ocupándose en el estudio y clasificación de las melodías de romance" 27 .

Más adelante, ya en 1930, se tiene noticia de que Torner viajó a Asturias con Menéndez Pidal para observar in situ y recoger descripciones y partituras de bailes y danzas tradicionales, así como los romances con que se acompañaban. Se supone que fue a partir de este viaje cuando Pidal se interesó en que Torner aportara sus melodías recogidas y transcritas de voz de los informantes al final de su Romancero hispánico.

Su relación con el centro se supone entonces sólo interrumpida por sus años de estancia en París (1912-1914), aunque Torner vuelve a Asturias y continúa sus recogidas en los veranos. Hacia 1914 ya colabora con Josefina Sela, gran recolectora de romances en Asturias ${ }^{28}$, quien a su vez le había descubierto el valor del romancero del norte peninsular a María Goyri, esposa y colaboradora de Menéndez Pidal (Catalán, 2001, 83 y III-xxiii). Más tarde publicará unas indicaciones para la notación musical de los romances, juntamente con las indicaciones para recogidas de textos de Goyri, y este folleto conocerá dos ediciones, una incluso posterior a su exilio ${ }^{29}$.

Lo que aporta Torner al CEH es el análisis musicológico de repertorios populares, trascendiendo así al otro gran recolector de melodías del $\mathrm{CEH}$, Manrique de Lara, cuya ocupación con respecto a los romances había sido la recolección y transcripción. También fue, en este sentido, más allá que otros compañeros músicos en la Residencia. Aunque algunos, como Bal y Gay, compartieron aficiones 
con él en cuanto a temas (v. g. Bal y Gay, 1939a, 1939b), no así su interés por la identificación y análisis musical de repertorios completos, que trascendía la mera transcripción de piezas. Con Manrique de Lara coincide en el interés por los romances y por la música antigua, así como por la relación entre ambos. En este último campo, sin embargo, Manrique de Lara no llega a aportar nada, a pesar de su manifiesto interés y sus numerosas notas tomadas para el $\mathrm{CEH}^{30}$, quizás por su muerte en 1929 -aunque Torner ya lo había sustituido en el CEH desde 1920- pero sin duda también por su falta de tiempo de dedicación, dadas sus numerosas obligaciones militares y diplomáticas.

Con sus trabajos de estudio de los romances (1923a, 1924a, 1924b, 1925, 1936, 1953), Torner sacó a la luz una serie de problemas, como la adaptación melódico-rítmica de la música al texto, la profundidad histórica y la pervivencia de temas, la complejidad y diversidad de las variantes, la pedagogía musical inspirada en temas populares, el ritmo interno del habla y del verso del romance, que no consiguió resolver totalmente a lo largo de sus investigaciones, pero que nunca dejó de tratar. En todos subyace su vocación musicológica de igualar en importancia el estudio de las melodías con el de los textos, y también en todos se refleja la influencia filológica en los objetivos y metodologías, con variados resultados.

Por todo ello, el repertorio de romances ilustra como pocos la curiosidad analítica de Torner, sus variadas influencias

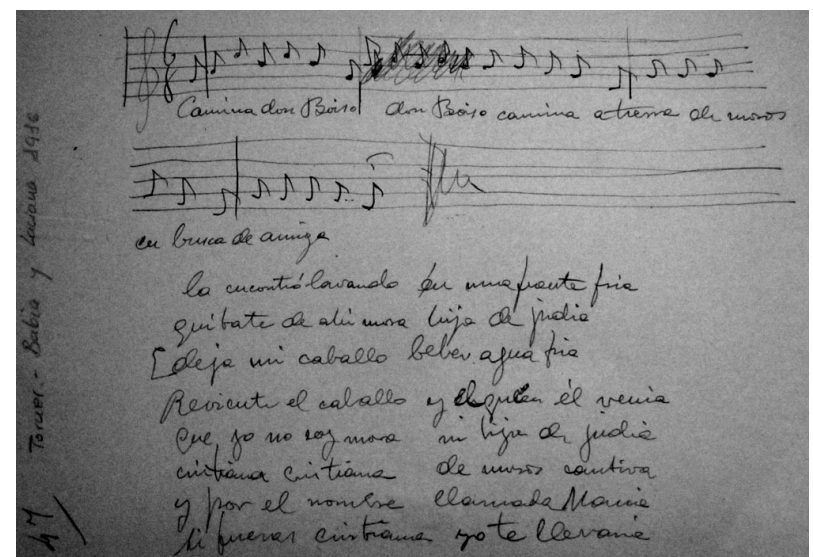

Figura 3. Romance de don Boiso, recogido en 1916 en la zona de Babia y Laciana por Torner: Archivo Menéndez-Pidal/Goyri, Madrid e intereses, además de la persistencia de una vocación interdisciplinar en sus investigaciones que se prolongará hasta el final de sus días ${ }^{31}$.

Sin embargo, sus mayores logros en este campo aún permanecen inéditos ${ }^{32}$. Tras su exilio forzado, los cientos de fichas que el musicólogo había juntado para sus análisis de la música de los romances se quedan en el Centro, y el volumen que se iba a hacer conteniendo estas músicas al final del Romancero Hispánico de Menéndez Pidal (1953) nunca llega a editarse, aunque éste lo cita en numerosas ocasiones por sus estudios de la música de los romances ${ }^{33}$. En 1930 anuncia que ya ha recopilado cerca de 1000 melodias de romance que pasarían a formar parte del Romancero General de Menéndez Pidal (Catalán, 2001, IV-xxxvii). La única obra que ve Torner publicada con su maestro es sin embargo la transcripción de unas cuantas melodias de acompañamiento para los textos del libro Flor Nueva de Romances Viejos $(1928 / 1933)^{34}$. Esta será la única vez que Torner publique con su maestro, a pesar de las más de dos décadas de colaboración conjunta, y esta será la obra que más difusión le daría al romancero entre los legos en la materia.

Además del romancero, otros asuntos musicales atrajeron la atención de Torner, especialmente las recopilaciones y análisis de repertorios de tradición oral (1931), las transcripciones de fuentes de música histórica (1923b) las cuestiones rítmicas subyacentes en canciones y textos literarios (1938b, 1938c, 1953, 1963), y las cuestiones de pedagogía y enseñanza musical (1924c, 1928, 1935a 1935b, 1948c). Su contribución al Congreso de Arte Popular de Praga, en 1928, versa sobre la "Bibliografía del folklore musical español" (La Época, 19/09/1928, p. 4) ${ }^{35}$, y más adelante participará también, junto a otros musicólogos, en el III Congreso de la Sociedad Internacional de Musicología (Barcelona, abril de 1936), en la sección dedicada al Folklore ${ }^{36}$. A partir de 1933 también formará parte de los colaboradores de la revista Musicografía, editada en Mónovar, junto con otros músicos y estudiosos como Turina, Julio Gómez, Millet, Nin, Pujol, Sáinz de la Maza, Subirá, Villar... y también fue uno de los "fotógrafos oficiales" del CEH en muchas de sus excursiones, dejando una pequeña colección fotográfica de tipos y paisajes, especialmente de Asturias.

Pero algunos de los trabajos que desarrolla en estos años nunca verán la luz. Es el caso de la descripción de la co- 


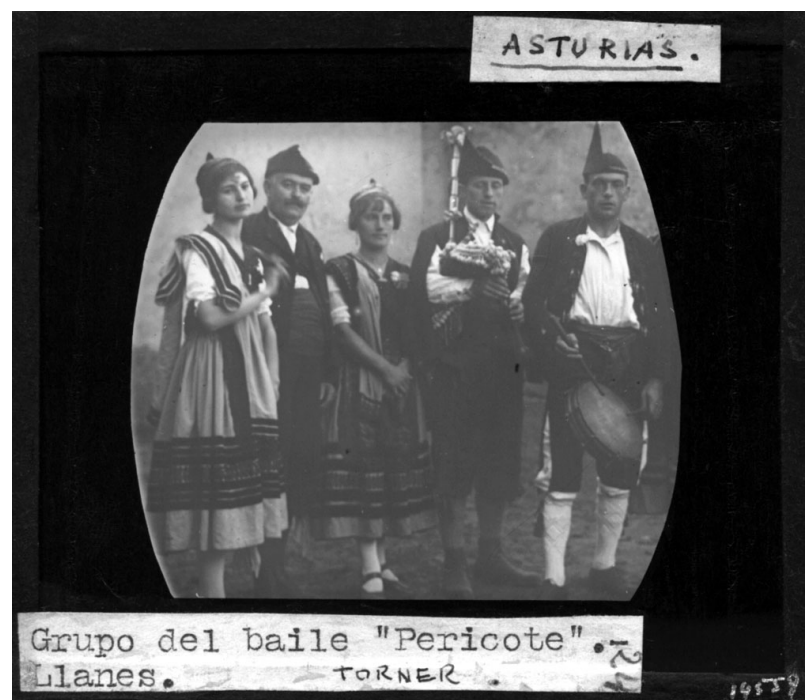

Figura 4. Grupo de baile asturiano "Pericote", sin fecha. Diapositiva de Linterna tomada por E. M. Torner. Fondo Gómez Moreno-Ricardo Orueta. Signatura c14559. Unidad de Tratamiento Archivístico y Documentación. CCHS-CSIC. (C) Archivo del Centro de Ciencias Humanas y Sociales, CSIC

lección de Barbieri de la Biblioteca Naciona ${ }^{37}$, realizada por Torner por encargo de Miguel Salvador, académico de Bellas Artes, y que le valió un premio de la Academia de San Fernando ${ }^{38}$. Otro volumen Ilamado Cantinelas Vulgares de la Biblioteca Colombina, de Sevilla, transcrito por Torner, también es mencionado como manuscrito final por Trend para anunciar su futura publicación, aunque no llegará a ver la luz $z^{39}$.

También es el caso del Cancionero de Turín, que Torner había trabajado en su dimensión musical, mientras que Bertini había tratado la literaria, y que quedó casi terminado pero inédito a la marcha de Madrid de Torner ${ }^{40}$. En una carta enviada a Homero Serís en Siracusa, EE.UU., Torner comenta desde Londres el 12 de abril de 1948:

"El Cancionero de Turín iba a ser publicado en el Centro por ese Sr. Bertini y por mí. Bertini tenía ya transcrita y creo que estudiada la parte literaria, y la musical, hecha por mí, quedó sin terminar. Bertini se fue a Italia pocos días después de iniciada nuestra guerra y no he vuelto a saber nada de él. Creo recordar que una copia de su trabajo literario quedó en el Centro guardado enla misma caja en que se hallaba la fotocopia del códice".
En la Memoria de la JAE 1934 se comenta que el señor Martínez Torner prepara un estudio, verificado con los materiales del Archivo [de la Palabra], sobre "La estética musical del cante jondo" (p. 237), pero este tema, que interesaba a Torner desde sus conversaciones con Ribera en los años 1910, también quedaría desaparecido con el cierre del Centro.

De los tratados inéditos a la muerte de Torner y comentados al principio de este artículo, el primero, Lírica Hispáni$c a$, fue editado y compilado por Homero Serís con la ayuda de Florentino ${ }^{41}$, hermano de Torner, y de la viuda de éste. Aunque se editó en España en 1966, todas las gestiones fueron realizadas desde Gran Bretaña, EE.UU. y México ${ }^{42}$. El segundo volumen, Rítmica Hispánica, está siendo transcrito por su autora en el tiempo en que este artículo ve la luz y de él se darán más noticias próximamente.

Como se ve, muchas de las inquietudes de Torner fueron canalizadas -especialmente las referidas a músicas populares- pero muchas otras quedaron en manuscrito, 0 desaparecieron, o aguardan aún en algún archivo desconocido. Una nota curiosa como epílogo a toda esta actividad de investigación es la mención en la ficha 2587 del Archivo de la JAE de la próxima celebración de un evento que dejaría clara para siempre la importancia del folklore para la academia. La ficha reza:

"Se celebrará el 12 de octubre de 1936 el Congreso de Folklore Hispánico. Vercomunicaciones del ministro de Instrucción Pública de 25 de marzo referente aeste asunto".

El congreso no se llegó a celebrar, pero coincidió en un momento importante en las investigaciones y trabajos de Torner. Por un lado, desde 1931 y hasta 1936 se habia involucrado profundamente con la dirección del Coro de las Misiones Pedagógicas y con las excursiones de éstas ${ }^{43}$. Por otro lado, en 1932 había sido nombrado profesor de "Prácticas de Folklore" en el Conservatorio de Madrid (una asignatura que entonces comenzó a impartirse como ayuda a la composición musical), puesto que en teoría seguía ocupando mientras estaba en Valencia en 1937 y luego en Barcelona en $1938^{44}$. Además, fue miembro de la Junta Nacional de Música primero (1931-1934) -y como consecuencia jurado en el Concurso Nacional de Música- y del Consejo Central de la Música después (1937-1939)45, y también había sido requerido como asesor del Museo del 
Pueblo Español en $1935^{46}$. En la década de 1930 Torner ya representa la vanguardia de la investigación académica sobre folklore en España, y sus numerosas menciones y relaciones con otras instituciones dan cuenta de que su trabajo estaba en un punto álgido, y tenía repercusiones internacionales, antes de la Guerra Civil.

Todas las actividades mencionadas en investigación fueron combinadas con una intensa actividad pedagógica, divulgadora y de colaboración con colegas e instituciones. $Y$ fueron estas dimensiones, de carácter popular e interdisciplinar, profundamente heterodoxas, las que más contribuyeron a la fama de Torner en vida, más incluso que las publicaciones de sus artículos y cancioneros. Son también hoy en día las que más preguntas nos plantean sobre los muchos intereses del erudito, del humanista y del intelectual comprometido políticamente con su conocimiento en un momento histórico de profundos cambios en España. También estas dimensiones explican muchos de los claroscuros en la historiografía de sus actividades, investigaciones y publicaciones, como se verá a continuación.

\section{TORNER Y LA DIVULGACIÓN MUSICOLÓGICA}

Durante su vinculación con la $J A E$, pero especialmente entre 1920 y 1937, Torner desarrolla una intensa actividad divulgadora en conferencias, conciertos, charlas, cursos y colaboraciones diversas, que complementa y da sentido a su actividad investigadora. Muchos de ellos estarán relacionados con homenajes y aniversarios significativos. La prensa madrileña lo cita asiduamente durante las décadas de 1920 y 1930, refiriéndose normalmente a él habitualmente como el "maestro Torner".

Su actividad más reseñada es la de conferenciante, pero dentro de esta se distinguen sus participaciones en cursos, sus conferencias (también aquellas que dirigió especialmente para la formación del público femenino), y las participaciones en homenajes y eventos. Respecto a su participación en cursos del CEH:

- Torner participa junto a A. Castro, Navarro Tomás, Solalinde, Díez Canedo y Torá en el "Curso para extranjeros" que organiza el CEH y que comienza el 16 de enero ( $L a$ Época, 02/01/1922, s. p.).
- La Voz anuncia el curso de diez conferencias de Torner sobre "La música popular española" que comienza el 28 de enero de 1922 (19/01/1922, p. 3)

- El "Curso para extranjeros" de otoño, en el que también participa Torner, es anunciado por La Época, y por $A B C$ (10/10/1922, p. 20), siendo su comienzo el 9 de octubre.

- $A B C$ menciona el comienzo del curso que impartirá Torner sobre "La música popular española" el 18 de enero de 1936, y comenta que se desarrollará en sábados sucesivos (15/01/1936, p. 60). Los contenidos de cada día del curso también serán reseñadas en este periódico $(A B C$, 18 y 25 de enero, 22 de febrero y 14 de marzo) y otros ( $L a$ Voz, La Libertad, El Sol...).

Sus charlas y conferencias fueron numerosísimas en Madrid a lo largo de los veinte años que permaneció ligado a la $J A E$, y entre ellas se entreveran algunas ofrecidas especialmente para el público femenino que deseaba formarse culturalmente, especialmente en la Residencia de Señoritas y el Lyceum Club Femenino ${ }^{47}$. Aquí se ofrecen algunas de las noticias que aparecen en la prensa sobre ellas:

-El 5 de noviembre de 1921 la conferencia "Música en España, siglos XII-XVII" tiene lugar en la Residencia de Señoritas Estudiantes, con ejemplos de violín y piano de transcripciones de las Cantigas, a cargo de Ribera y de vihuelistas españoles, a cargo de Torner (El Sol, 06/11/1921, p. 2).

- La Acción anuncia la velada artística para el 14 de mayo de 1922, con conferencia de Torner acompañado por el violinista Jiménez, a la que seguirá un concierto (13/05/1922, p. 2).

- El Heraldo de Madrid da cuenta de su próxima conferencia sobre los vihuelistas españoles del siglo XVI, el 9 de abril de 1924, organizada por el CEH y con ilustraciones musicales a dos voces y piano (08/04/1924, p. 5 ; también reseñado en La Libertad y $A B C)$. Unos años más tarde, Torner publica el artículo divulgativo "Los vihuelistas del siglo XVI" en el periódico $A B C(08 / 02 / 1931$ pp. 13-14).

- $A B C(20 / 04 / 1926$, p. 13) reseña su conferencia "La música popular asturiana. Su valor tradicional. Con ejemplos interpretados por cantores regionales" el 19 de abril de 1926, acompañada de cantos de "El Botón", para la clausura de la exposición de artistas asturianos, organizada 
por El Heraldo de Madrid y el Centro Asturiano. También reseñada por El Heraldo... y La Época.

- El Sol anuncia una conferencia, organizada por el Lar Gallego en Madrid, de Torner junto a Bal sobre "Folklore Musical Gallego" (18/06/1931, p. 4). Sobre este tema, y además de sus publicaciones académicas, Torner también escribe en el periódico $A B C$ un artículo divulgativo titulado "Andanza por Galicia" (04/01/1931, pp. 19-21).

- La Voz da cuenta de una serie de conferencias que impartirá Torner sobre la canción española, ilustradas con "proyecciones y versiones musicales auténticas" (18/02/1932, p. 6; también reseñado por La Libertad).

- El 11 de mayo de 1932 la conferencia "Cancionero tradicional castellano" tiene lugar en el Lyceum Club Femenino (La Libertad, 11/05/1931, p. 9).

- El jueves 16 de marzo de 1933 Torner imparte la conferencia sobre "Lírica tradicional" en el Conservatorio Nacional de Música y Declamación (El Heraldo, 14/03/1933, p. 5; también reseñada en $L u z$ y $A B C$ ).

- La conferencia "La música y los bailes asturianos" tiene lugar en el seno de la Exposición de carteles por Asturias, que se inaugura el 19 de mayo de 1933 (El Sol, 14/05/1933, p. 4).

- El Heraldo de Madrid anuncia las actividades que se realizan en el Lyceum Club Femenino desde el 23 de marzo al 26 de mayo de 1935 para conmemorar el aniversario de Lope de Vega (19/03/1935, p. 6). Torner y Castro Escudero imparten una conferencia el día 4 de mayo, que también será reseñada en Mundo Femenino y La Libertad.

- El 15 de mayo de 1935 Torner da una conferencia sobre el folklore musical castellano en Unión Radio, acompañado por Agapito Marazuela, que interpreta algunos temas tradicionales a la dulzaina (Ondas 06/07/1935, p. 4). El 18 de febrero de 1936 repetirá sede con la conferencia sobre la danza española en el siglo XVII, con ilustraciones musicales interpretadas por un cuarteto de instrumentos españoles de bandurria, laúd y guitarras (La Libertad, 18/02/1936, p. 10).

- La sección artístico-musical de la Asociación de Alumnas de la Residencia invita a Torner a dictar una conferencia sobre "Los ritmos de la música popular española" el 28 de abril de 1936 ( $A B C, 25 / 04 / 1936$, p. 40).

- El Sol reseña su conferencia en Llanes, Asturias, como director del coro de las Misiones Pedagógicas sobre "La educción melódica y folklórica en la escuela rural" (03/06/1936, p. 5), en el seno de la Semana Pedagógica de Escuelas Rurales de Llanes.
La última conferencia de Torner de que se tiene noticia antes de la guerra es sobre música popular española, y es dictada en la significativa fecha del 16 de julio de 1936 en el Centro de Estudios Históricos (El Sol, 17/07/1936, p. 7).

Respecto a la participación de Torner en las celebraciones, homenajes y aniversarios diversos, todos de carácter cultural y/o artístico, su actividad fue realmente intensa. Además de su participación ya mencionada en las actividades que acompañaron a la exposición de artistas asturianos que organizó El Heraldo de Madrid en 1926, Torner organizó con el Grupo Escolar Cervantes una audición de música antigua y popular española, arreglada por él mismo, en honor del pedagogo belga A. Sluys, que visitó Madrid en 1922 (La Época, 19/05/1922, p. 2; también reseñada por El Heraldo de Madrid). Asimismo es parte de la comisión organizadora del almuerzo-homenaje a Evaristo Valle el día 22 de mayo de 1923, con motivo de su exposición en Madrid (La Voz, 20/06/1923, p. 2). En 1926 participa en la "Fiesta de exaltación de la canción castellana", organizada por El Heraldo de Madrid, con la conferencia "La canción tradicional castellana"48, con ejemplos cantados por Alberto Anabitarte y María Teresa Muedra, que se celebra el 28 de noviembre (El Heraldo, 27 de octubre al 29 de noviembre de 1926; también reseñada por El Sol, La Época, La Libertad, El Globo, La Voz, ABC, El Imparcial, El Año Académico y Cultural...).

En 1927, el año del aniversario gongorino que dio nombre a la Generación del 27, Torner publica su artículo dedicado a Góngora, que "es, de su tiempo, uno de los poetas que mayor documentación ofrece al folklorista" (Torner, 1927, $417)^{49}$. Con este estudio consolida el que será uno de los hilos conductores de su investigación hasta sus últimos días, la vinculación entre los documentos históricos y la tradición oral ${ }^{50}$.

En sucesivos aniversarios, especialmente el celebrado en 1935 por el tricentenario de la muerte de Lope de Vega, Torner ensaya esta vinculación en todo tipo de representaciones teatrales, charlas, y conciertos. En este caso aparece en diferentes actividades relacionadas: es el transcriptor de varios fondos musicales del siglo XVII que son utilizados en el concierto-recital de Aúrea de Sarrá $(A B C, 18 / 10 / 1935$, p. 25); da la última conferencia del ciclo sobre arte español organizado por el CEH con el 
título "La música en la época de Lope" ilustrada con un concierto dirigido por él mismo el 5 de diciembre de 1935 $(A B C, 24 / 11 / 1935$, p. 55); también aporta los arreglos musicales a algunas de las representaciones teatrales del Conservatorio de Madrid.

Otras celebraciones menores en las que el maestro cede sus obras y arreglos para ser interpretados, bajo su dirección o la de otros durante los años treinta son, al menos, las siguientes: la inauguración de la estatua del Arcipreste de Hita en el Alto del León, cerca de Tablada; el Festival de los Cigarrales de Toledo; la Semana de la Historia del Derecho; la inauguración de la carretera que une el monasterio del Paular con Miraflores de la Sierra; la inauguración de la Fuente Cossio; la Semana del Libro; la fiesta del presidente de la República a los escolares madrileños en el Campo del Moro; la fiesta en el Teatro Español organizada por la Cámara Oficial del Libro...

Su labor al frente del coro de las Misiones Pedagógicas fue tratada asimismo en la prensa de su época de manera frecuente entre 1931 y 1936, al menos en los periódicos ABC, La Voz, Crónica, Nuevo Mundo, Luz, Mundo Gráfico y Estampa, aunque siempre en relación con el trabajo desarrollado por las Misiones en la España de la época, especialmente cuando llegaban a lugares remotos y de difícil acceso y comunicación. En una de las últimas noticias que aparecen sobre el tema, sin embargo, se anuncia la intención de formar una orquestina en las Misiones, bajo la dirección del musicólogo, y de utilizarla para llevar el cine sonoro a las residencias infantiles (La Libertad, 05/08/1936, p. 7).

Sus colaboraciones con otros músicos sí fueron comentadas de manera particular y exhaustiva en muchos casos, y también sus relaciones con algunos de los artistas y agrupaciones musicales de su tiempo. A modo de ejemplo:

- El Heraldo de Madrid da noticia del recital de guitarra de Sáinz de la Maza con obras de vihuelistas del siglo XVI, entre las cuales figuran algunas transcritas por el maestro Torner (04/12/1922, p. 3).

- El Sol se hace eco de la presentación del Orfeón de Mieres en Madrid, tutelada por el musicólogo (05/12/1926, p. 4; también reseñada por ABC, La Época, El Heraldo, La Voz, El Imparcial...). El Heraldo de Madrid reseña más adelante el concierto del Orfeón de Mieres interpretando piezas de Torner (11/11/1928, p. 6). Las actuaciones de este coro en Madrid y su relación con el maestro, tendrán eco en diferentes periódicos a lo largo de los años 1930, pero también otros coros interpretan sus piezas y aparecen en la prensa con frecuencia por ello. Es el caso del Orfeón Ovetense, el Orfeón Gijonés, o la Masa Coral Normalista de Valencia.

- $A B C$ anuncia el estreno de la película de ambiente asturiano dirigida por Manuel Noriega y con música y arreglos de Torner Bajo las nieblas de Asturias (15/01/1927, p. 32). La Libertad también reseña este estreno, comentando que en su proyección los coros asturianos interpretan canciones seleccionadas y arregladas por él (23/02/1927, p. 6$)^{51}$.

- $A B C$ anuncia el concierto para la "Protección al Trabajo de la Mujer" con un programa completo compuesto de piezas del cancionero popular transcritas por Torner, todas ellas interpretadas por señoritas (04/12/1927, p. 42).

- La Voz lo menciona como autor de varias de las piezas interpretadas por La Argentinita en la velada en honor de los niños de la Inclusa el 19 de abril de 1933 (19/04/1933, p. 3). Esta artista también interpreta piezas suyas en el Teatro Español y en diferentes obras benéficas (reseñadas en La Libertad y La Voz).

- La cantante Laura de Santelmo triunfa en Bruselas con un repertorio que incluye piezas de Torner y Castro Escudero ( $A B C, 17 / 05 / 1936$, p. 60).

Aunque sin duda su actividad fue más allá de la reseñada por la prensa, ésta se hizo eco de muchas de sus otras colaboraciones, como por ejemplo su participación en las "veladas familiares" de los jueves que organizaba el Grupo Escolar Cervantes en Madrid, donde colaboró aportando sus canciones tradicionales recogidas y sus arreglos musicales (La Libertad, 05/03/1927, p. 2). 0 su apoyo en una carta abierta, firmada por muchos otros músicos también, al musicólogo Richard H. Stein, duramente criticado por los comentarios laudatorios que había hecho sobre el libro de José Subirá La música en la Casa de Alba (La Libertad, 30/01/1929). También el encargo hecho desde la Residencia de Estudiantes de ocuparse de la audición de canciones eslovacas que tuvo lugar en junio de 1931 (El Sol, 10/06/1931, p. 3), o su responsabilidad en la organización de la parte musical de las fiestas extraordinarias que celebra Toledo en honor de Lope de Vega ( La Voz, $25 / 05 / 1935$, p. 3$)$. Incluso sus arreglos para la obra teatral 
"La Serrana de la Vega" de Vélez de Guevara, estrenada en el teatro Español...

\section{Epílogo}

La última noticia que se conoce sobre Torner antes de su exilio definitivo, aparece en el número 5 de la Revista Hispánica Moderna, en 1939, pero en ella ya no se comentan sus actividades de investigación o divulgación, ni su participación en eventos académicos y sociales diversos. La noticia habla de la vida de algunos exiliados españoles relacionados con la literatura, primero en Barcelona y luego en sus sucesivos destinos. Se comenta la estancia en Barcelona de Antonio Machado, donde organizaba tertulias a las que asistian asiduamente tanto Torner como Navarro Tomás, y el posterior exilio de Torner a Londres, donde equivocadamente es ligado a una universidad inglesa.

Antes de su estancia en Barcelona, Torner llega a Valencia con otros colegas del CEH. Allí todavía sigue colaborando con Castro Escudero, antiguo colega del Conservatorio y del CEH, y publica en 1938 las Danzas Valencianas. Su interés por las danzas como fuentes históricas continúa más tarde en Londres, donde publica las Cuatro danzas españolas de la época de Cervantes (1947). De Valencia se traslada a Barcelona en 1938, y allí colabora con la revista Música en dos de sus cinco números publicados, todos ellos en el mismo año. De Barcelona pasa a Francia, y de allí será trasladado a Londres junto con otros muchos intelectuales y estudiosos españoles ligados a la República.

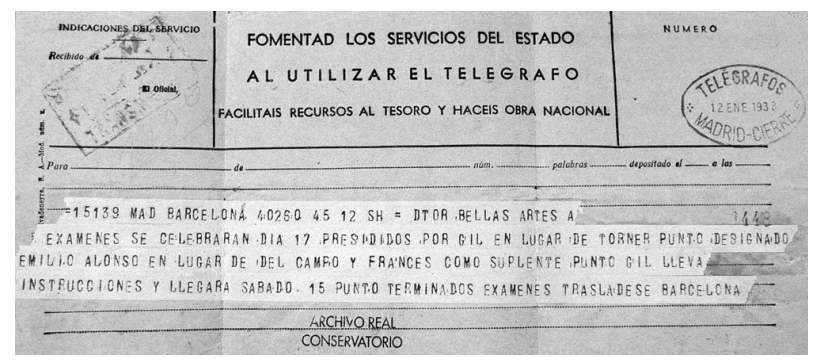

Figura 5. Telegrama del 12 de enero de 1938 en el que se exime a Torner y a otros compañeros, entonces ya en Barcelona, de ir al Conservatorio de Madrid a realizar los exámenes correspondientes. Archivo Histórico, Real Conservatorio Superior de Música de Madrid
No deja de sorprender, visto el número, la variedad y la importancia de sus diferentes aportaciones a la historia y el análisis musical, y su intensísima actividad divulgadora, el silencio que se extiende sobre el maestro Torner tras su exilio en 1939, e incluso tras su muerte en 1955. Si en Asturias, su tierra natal, se han publicado noticias sobre él, libros-homenaje, y se le ha recordado con diferentes eventos en los aniversarios de su nacimiento y muerte, en Madrid, donde desarrolló la mayor parte de su actividad investigadora ligado a la JAE, apenas se le recuerda ni por sus publicaciones ni por sus actuaciones y colaboraciones.

Es difícil imaginar que este olvido sea totalmente inocente. La guerra y la dictadura silenciaron su obra en España por su apoyo incondicional al gobierno de la República, pero los estudiosos posteriores apenas han penetrado críticamente en su inmensa obra, ni en sus actuaciones socioculturales, de enorme impacto social en su época y actuales referentes históricos. Quizá ello sea porque los materiales que trabajó y publicó -así como sus cartas, papeles y piezas musicales- siguen dispersos en varios países, alojados en diferentes archivos públicos y privados y, mayormente, sin clasificación alguna. Quizá también porque sus heterodoxas investigaciones, y especialmente las que dejó sin publicar sobre música antigua, fueron sin duda muy bien aprovechadas por algunos de los nuevos integrantes de la musicología española, especialmente desde el Instituto Español de Musicología (IEM, fundado en 1943 en Barcelona en el seno del CSIC, y heredero material, aunque no espiritual, de la JAE y del CEH). De hecho, la conexión entre la música tradicional y la música histórica o culta fue una de las líneas de trabajo que se establecieron desde el principio en el IEM, y también desde allí se coordinaron las llamadas "misiones de campo" (a imitación sólo nominal de las "misiones pedagógicas") para continuar la recogida de piezas tradicionales por España, especialmente durante los años 1940.

Las diferentes políticas disciplinares que tanto afectaron su aproximación y enfoques de investigación, en el seno del grupo de trabajo de Menéndez Pidal, fueron cambiando con los años, pero su labor siempre estuvo a caballo entre varias disciplinas -filología, musicología, historia...- y entre varios mundos académicos $-\mathrm{CEH}$, conservatorio, museos y archivos- y, por tanto, entre diferentes núcleos de poder institucional. De esta manera, Torner nunca fue un investigador estándar, ni por sus estudios ni por sus inte- 
reses y metodologías; su probidad y erudición suscitaron recelos entre algunos colegas, y su profunda vocación interdisciplinar no dejó de incomodar a muchos estudiosos de su tiempo, que veían en él un intruso ${ }^{52}$.

Su figura también fue polémica por su decidido apoyo a la mujer -y especialmente a la mujer trabajadora-, por su laicismo expreso, y por su implicación personal en la formación y educación de las poblaciones más humildes. Es decir, sus ideas fueron quizá demasiado modernas para su época, pero en la actualidad parece que aún siguen siéndolo. Algunos de los males de su época que el maestro combatió en vida siguen hoy presentes: formación muy desigual en función del lugar de nacimiento y educación, menos posibilidades de formación y desarrollo laboral para la mujer, falta de separación de los poderes político y religioso en la vida civil, ninguneo de las culturas tradicionales de transmisión oral en la academia... En este sentido, Torner sigue siendo profundamente moderno, más aún quizá tras el paso del tiempo por su vida y su obra y, de esta manera, su figura no puede -al menos aún- perder la dimensión política que tuvo en vida.

\section{NOTAS}

1 Para una biografía más personal de la vida de Torner (Oviedo 1888-Londres 1955) se pueden consultar fundamentalmente González Cobas (s.f.) y Mallo (1980).

2 La carta forma parte actualmente de los fondos de la Residencia de Estudiantes, y puede consultarse en el Archivo de la JAE (1907-1939), http://archivojae.edaddeplata.org/.

3 Su hijo Eduardo, del que se había separado en 1939 en Francia y que tiempo después había regresado a España, nunca tendrá permiso en vida de su padre para ir a Gran Bretaña. La esposa de Torner, Jovita Cué, y su hija se habian quedado en Asturias, donde les sorprendió el alzamiento en 1936, y tardaron más de una década en poder viajar a Londres a reunirse con Torner.

4 Para una información completa sobre la gestación y desarrollo del CEH (1910-1939) se pueden consultar entre otros López Sánchez (2006), Castillejo (1997-1999), Catalán (2001), y las Memorias y Anales de la Junta de Ampliación de Estudios e Investigaciones Científicas.

Recibido: 10 de diciembre de 2010 Aceptado: 15 de febrero de 2011
5 Foulché-Delbosc propuso a Menéndez Pidal la colaboración para la realiza- ción conjunta de un romancero español "viejo" (recogido en las fuentes escritas conservadas en varios lugares de Europa), pero los trabajos del primero no tenían en cuenta las nuevas teorias de Pidal acerca de la vigencia del romancero en la tradición oral que sus encuestas le habían probado, y no estaba, por consiguiente, interesado en incluir el romancero "moderno" (vivo en la tradición oral) como contrapunto contextual. Finalmente la obra conjunta no verá la luz y, hacia 1912, se producirá la ruptura de relaciones académicas entre ambos por sus posturas cada vez más encontradas (Cid, 1993, 135, nota 16).

6 La Libertad anuncia los cursos para extranjeros que organiza el $\mathrm{CEH}$, incluyendo una conferencia de Pidal acompañado al piano por Torner y a la voz por la señorita Benedito (18/07/1926, p. 6). Este mismo periódico anuncia el 2 de diciembre de 1926 la noticia de la conferencia en el que el maestro Pidal se acompaña de nuevo con el piano de Torner y las voces de la señorita Muedra y el señor Anabitarte (p. 6; también reseñado en $A B C$, El Sol, La Voz y $L a$ Correspondencia Militar).

7 Aunque en España Menéndez Pidal fue el pionero en adjuntar las me- 
lodias a los textos romancísticos, en otros lugares de Europa investigadores como Cecil Sharp, Anne Geddes Gilchrist, Marius Barbeau o Phillip Barry ya habían incorporado melodías a sus colecciones de baladas a finales del siglo XIX (Prat, 2008, 236).

8 Hay que tener en cuenta que en estos años la principal "utilidad" académica de la recolección del folklore musical aún era auxiliar con melodías y ritmos vernáculos a las composiciones de música culta, dotándolas de un carácter "nacional". El análisis musicológico que Torner propuso era totalmente nuevo en los usos académicos españoles y extraño aún en la mayoría de los circuitos internacionales.

9 A Manrique de Lara le fueron concedidas varias pensiones (1911-1912, 1918, y 1923), aunque no llegó a disfrutar de la última de ellas. Datos procedentes del Archivo de la JAE (1907-1939), loc. cit.

10 El 14 de febrero de 1936 Torner será mencionado junto a Trend, Mitjana, Subirá y Pedrell como transcriptor de vihuelistas españoles de los siglos XVI y XVII y referencia internacional en el tema. El artículo de Adolfo Salazar en El Solse titula "La música de nuestros vihuelistas en discos. Los criterios acerca de las transcripciones" (p. 2).

11 Martínez Torner recibió el encargo de la "Comisión de Estudios Gallegos" de la JAE de recopilar el Cancionero de Galicia. Para ello contaría con la ayuda de Bal y Gay. El trabajo fue realizado durante los veranos de 1928 a 1932, en el que ambos recorrieron las cuatro provincias consultando los archivos y recogiendo gran cantidad de piezas transcritas in situ. El trabajo no fue completado para su publicación y con la Guerra Civil, las fichas se extraviaron. Finalmente serían encontradas y rescatadas por $H$. Anglès para el Instituto Español de Musicología (Barcelona) -que heredaría parte de los materiales del desaparecido $\mathrm{CEH}$ - y se editaría con la colaboración de instituciones y estudiosos gallegos, primero en 1973 $\mathrm{y}_{1}$ en una edición más completa $\mathrm{y}$ revisada, en 2007 (cf. Ascot \& Bal y Gay 1990; Villanueva 2006, 2007; Asensio 2008).

12 Algunas de estas colaboraciones son representadas por el Teatro Escuela de Arte, fundado por Cipriano Rivas Cheriff, y en el que tanto Torner como Castro Escudero son asesores musicales ( $L a$ Voz, 21 de enero de 1935, p. 5). Su colaboración más mencionada fue en la reconstrucción de una dan$z a$ de arcos a partir de documentos de los siglos XVI y XVII (EI Sol, 25 de junio de 1935, p. 2; La Voz, 23 de marzo de 1935, p. 3). En el aniversario de Lope de Vega, tanto Torner, como Castro Escudero y Bal y Gay son reseñados como responsables del renacimiento de la música española antigua, gracias a sus estudios, investigaciones y transcripciones $(A B C$, 23 de marzo de 1935, p. 52).

13 Bal y Gay relata en su libro de memorias la visita de Curt Sachs a Barcelona, cuando lo conoció y le transmitió sus dudas acerca de los criterios de transcripción de Martínez Torner, y cómo Sachs le dio la razón en sus criterios y prometió comentárselo a Menéndez Pidal. Al parecer, la consecuencia de estas conversaciones fue la diversificación de las tareas de uno y otro, asignándole al gallego el estudio de las fuentes históricas, mientras que el asturiano se dedicaria a las fuentes de tradición oral (Ascott \& Bal y Gay 1990: 96-97). Esta visita tuvo lugar una vez completadas las recolecciones de ambos en Galicia, pero antes de la Guerra Civil, probablemente en 1936.

14 A diferencia del caso español, el folklore se integró tempranamente en la academia anglosajona y a lo largo de todo el siglo XX desarrolló notables investigaciones y creo destacadas escuelas (cf. Prat, 2008).

15 Archivo de la JAE (1907-1939), loc. cit. Expediente E. Martínez Torner JAE/96-389.

16 Real Decreto de 22 de enero de 1910 aprobando el Reglamento de la Junta, aparecido públicamente en la $G a$ ceta de 28 de enero.

17 No hay que olvidar que la práctica musical, y luego la musicología, estuvo ligada en España hasta épocas muy recientes con la educación impartida por religiosos en seminarios e iglesias, poco abierta en general a las nuevas corrientes intelectuales y las nuevas prácticas disciplinares.

$18 \mathrm{El}$ estreno de La promesa aparece reseñado al menos en $A B C, E I$ Sol, Blanco y Negro, El Heraldo de Madrid, La Voz, La Época, El Imparcial, La Correspondencia Militar, El Siglo Futuro... (en abril y mayo de 1928) que también recogen el posterior estreno de La Maragata (en febrero y marzo de 1931).

19 Esto no sucedió con todas las disciplinas, sino con aquellas más marginales como la musicología. En otros ámbitos, como el literario, el reconocimiento de la tradición no necesariamente religiosa dio lugar a importantes grupos de vanguardia, como sería la Generación del 27.

20 Memorias de la JAE 1916-1917, pp. 96 y 109 (adscripción al centro, y trabajo de folklore en el Alto Aragón); 1918-1919, pp. 107, 118, y 299 (adscripción, trabajo sobre melodias de romances, y concierto); 1920 
1922, pp. 119, 298, у 300 (adscripción, y conciertos); 1922-1924, pp. 151, 158, 161, 164, 169, 170, у 297 (adscripción, edición de Narváez, curso sobre vihuelistas y conferencia sobre música española, y artículo en la RFE); 1924-1926, pp. 203, у 216 (adscripción, y viaje a Cuba y México); 1926-1928, pp. 145, 157, 158, 177, y 179 (adscripción, publicación del artículo de Góngora, trabajo sobre música española, publicación del cancionero de los siglos XV y XVI); 1928-1930, pp. 155, 166, 190, 295, 296, y 448 (adscripción, recogidas en Galicia, publicación con Goyri, conferencia de Torner y Bal sobre Galicia); 1930-1932, p. 131 (adscripción); 1931-1932, pp. 144, 268, y 402 (recogidas en Galicia); 1933-1934, pp. 218, 232, 233, 236, у 395 (adscripción, comienzo del Cancionero gallego, trabajos en el Archivo de la Palabra, y recogidas en Galicia). Archivo de la JAE (1907-1939), loc. cit.

21 Memorias de la JAE 1922-1923, p. 164. Archivo de la JAE (1907-1939), loc. cit.

22 Memorias de la JAE 1926-1928, pp. 276 y 405, correspondientes a 1928 (recogidas de Torner en Galicia), pero con apariciones esporádicas en memorias anteriores, mencionadas en nota . $^{\circ} 20$, vid. supra.

23 Memorias de la JAE 1933-1934, p. 394 , correspondiente a 1934, cuando las recogidas de músicas y textos en Galicia de Torner y Bal y Gay ya habian terminado.

24 A pesar de la intensidad de trabajo de Torner desde su llegada al CEH, la consolidación de su actividad en el campo del Folklore a nivel institucional da, sin embargo, algunos años más tarde, con la creación en 1930 del Archivo de la Palabra, dirigido por Tomás Navarro Tomás y con Martínez
Torner al frente de la sección de música (vid. Valverde 1998).

25 Memoria de la JAE 1934, p. 236. También en $E /$ Sol, 11/05/1933, p. 10; y en Estampa, 28/10/1933

26 Archivo de la JAE (1907-1939), loc. cit.

27 Las Memorias de la JAE dan cuenta sólo de algunas de las actividades de Torner.

28 Los romances recogidos por Sela en Asturias son fundamentalmente textos; cuando la música aparece, es anotada por Torner.

29 María Goyri había publicado sus "romances que deben buscarse en la tradición oral" en 1906, pero las publicaciones que también incluian las "indicaciones" de Torner serán posteriores (Goyri y Torner, 1929, 1945).

30 Gran parte de sus numerosísimas piezas recogidas y de sus notas se conservan en la Fundación Archivo Menéndez Pidal/Goyri, Madrid, aunque aún no existe una edición comprensiva de todos sus materiales.

31 Para un recuento más detallado de sus investigaciones en el campo del romancero vid. Asensio (2010, 21-31, 49-62).

32 Recordamos aquí que las recopilaciones de romances realizadas por Torner permanecen sin publicar en su mayoría. Las partes musicales asturianas y gallegas son las únicas completamente editadas (Asensio, 2010, 63-201; Torner, 1973/2007), pero aún quedan músicas y textos sin publicar recogidos en el Alto Aragón, Castilla y León, Castilla-La Mancha y Andalucía.

33 Las citas correspondientes al primer tomo están en las páginas siguientes: p. 90 (nota 16), y p. 147 (adición a la nota 16). Las correspondientes al segundo tomo son: p. 82 (nota 35), p. 300 (texto y nota 12), p. 329 (en el texto), p. 367 (nota 4). Aunque en sus primeros recuentos de temas romancísticos del CEH (1910) Pidal cita a Manrique de Lara como el mayor recopilador de romances, en 1952 en su Romancero Hispánico cita ya a Torner como su más prolífico colaborador musical, por sus numerosas recogidas, transcripciones y análisis de piezas, tanto propias como recogidas por otros.

34 La primera edición del libro es de 1928, aunque las partituras se incorporarán a partir de la segunda edición, en 1933.

35 Su contribución bibliográfica al folklore español es examinada por Katz (2004).

36 Existe información especifica sobre este congreso en Contreras (2009).

37 En 1916 Torner obtiene una beca de la Diputación de Oviedo para estudiar los cancioneros históricos de la Biblioteca Nacional.

38 Adolfo Salazar recoge la designación de Torner para la realización de este trabajo en un artículo titulado "Musicología póstuma: Pedrell, Mitjana Villalba" (El Sol, 23/08/1923, p. 4). Una década después, el mismo crítico vuelve a mencionar a Torner como el musicólogo que mejor ha descrito los manuscritos inéditos de Barbieri, y vuelve a reclamar la publicación de la descripción de Torner para beneficio de los investigadores interesados; lo hace en su artículo "Musicólogos. La República y el Cancionero de Barbieri" (El Sol, 14/04/1933, p. 35).

39 La mención de Trend se produce en 1929, en un artículo para la revista Music \& Letters. Sin embargo, e Cancionero Musical de la Colombina no será publicado hasta 1971, por M. Querol, colaborador de Anglés.

40 Las noticias sobre este cancionero y e papel de Torner en él también se reco- 
gen en el artículo publicado por Bertini en 1938. Las notas de Torner nunca fueron localizadas, pero el Cancionero de Turín fue publicado años más tarde, también por Querol (1989).

41 El volumen se formó a partir de las publicaciones de Torner en la revista Symposium, de EE.UU. (1946, 1947a, 1947b, 1948a, 1948b, 1949 y 1950).

42 Existe abundante correspondencia en los años 1950 y 1960 concerniente a la publicación de este manuscrito. Esta correspondencia está siendo localizada y transcrita, junto con materiales provenientes de diversos fondos, para una edición futura del epistolario completo de Torner.

43 Para documentar la participación de Torner en las Misiones Pedagógicas, vid. Pliego de Andrés, 2006.

44 Entre la documentación existente en el Real Conservatorio Superior de Música de Madrid, se encuentra un telegrama dirigido a Torner en Valencia, enviado desde el Conservatorio el 12 de enero de 1938, y en el que se le excusa de ir a Madrid para la celebración de los exámenes (Archivo Histórico Administrativo, serie "Asuntos generales", legajos de 1938). Vid. también Presas (20032004, 55-104).

45 La Junta Nacional de Música y Teatros Líricos es creada en 1931 para ocuparse de todos los asuntos relacionados con la educación, la difusión y la colaboración musical en el país. Su vida es corta pero muy polémica, ya que muchos de sus integrantes también se dedicaban a actividades musicales, y termina en 1934 con la dimisión de todos sus miembros ( $L a$ Voz, 12/02/1934, p. 3). En 1937 es creado el Consejo Central de la Música con análogas intenciones $(A B C$, 26/06/1937), pero la Guerra Civil impide su funcionamiento real.
46 El Heraldo de Madrid, 12/03/1935, pp. 2 y 16 .

47 Ambos centros serian clausurados al final de la Guerra Civil. Su vida fue corta pero muy intensa: Residencia de Señoritas (1915-1939), Lyceum Club (1926-1939).

48 Esta conferencia también será titulada por diferentes medios como "Romancero castellano" o "Evolución del cancionero castellano".

49 La aparición del número monográfico dedicado a Góngora de la Revista de Filología Española será reseñado en la prensa por El Sol (11/11/1928, p. 2), pero también por la revista especializada La Gaceta Literaria.

50 Aunque Torner no publicará nada más sobre Góngora, seguirá trabajando en las conexiones entre literatura y música popular y culta. El tema de la música en relación con Góngora es retomado años más tarde también por Querol (1975).

51 Vid. también Lorenzo (1991).

52 Sus acercamientos a la música antigua le valieron algunas polémicas con Anglés, y con Bal y Gay, pero también su extenso trabajo en Galicia fue ninguneado durante décadas, y muchos de sus trabajos inéditos aguardan revisión y publicación.

53 El texto da origen a esta publicación fue leido en 2009 y publicado en 2011, aunque la revista lleva, por cuestiones de retraso interno, la fecha de 2008.

\section{BIBLIOGRAFÍA CITADA}

Asensio Llamas, Susana (2008): "Eduardo M. Torner: el romancero musical asturiano y sus colaboraciones con Galicia", El Museo de Pontevedra 62: $147-170^{53}$.
- (2010): Fuentes para el estudio de la música popular asturiana. A la memoria de E. M. Torner, Madrid: CSIC-Universidad de Oviedo.

Bal y Gay, Jesús (1939a): Romances y viIlancicos españoles del siglo XVI: dispuestos en edición moderna para canto y piano, México: La Casa de España en México.

Bal y Gay, Jesús (1939b): "Fuenllana and the Transcription of Spanish Lute Music", Acta Musicologica 11: 16-27.

Bertini, Giovanni Maria (1938): "Un romancero musical español en la Biblioteca Nacional de Turín (Italia)", Aevum 12/1: 56 (enero-marzo).

Castillejo, David, ed. (1997-1999): El epistolario de José Castillejo. Los intelectuales reformadores de España, Vol. 1. Un puente hacia Europa, 1896-1909vol. 2. El espíritu de una época, 19101912 - vol. 3. Fatalidad y porvenir, 1913-1937, Madrid: Castalia.

Catalán, Diego (2001): El Archivo del Romancero: historia documentada de un siglo de historia, 2 vols., Madrid: Fundación Ramón Menéndez Pidal.

Cid, Jesús Antonio (1993): "El Romancero oral en Asturias. Materiales de Josefina Sela y E. Martínez Torner: Inventario, Índices, Antología", Revista de Dialectología y Tradiciones Populares 48: 1, 175-245.

Contreras Zubillaga, Igor (2009): "Ciencia e ideología en el III Congreso de la Sociedad Internacional de Musicología (Barcelona, 18-25 abril de 1936)", en M. Nagore, L. Sánchez y E. Torres (eds.), Música y cultura en la Edad de Plata. 1915-1939, Madrid: ICCMU, pp. 143-156.

García Ascot, Rosita, y Jesús Bal y Gay (1990): Nuestros trabajos y nuestros días, Madrid: Fundación Banco Exterior.

Gómez Rodríguez, José Antonio (1989): "La España de plata de Eduardo Martínez 
Torner, 1888-1955", Cuadernos de Música y Teatro, 3, 53-72.

- (2006): "La obra (etno)musicológica de Eduardo Martinez Torner", en Conferencias en homenaje a Eduardo Martínez Torner, Oviedo: RIDEA, 81122.

- (2009): "El Cancionero musical de la lírica popular asturiana, de Eduardo Martínez Torner, y la recopilación de música tradicional española en la primera mitad del siglo XX", en Actes del II Conceyu Internacional de Lliteratura Asturiana (CILLA), 2007, Oviedo: Academia de la Llingua Asturiana, 49-72.

González Cobas, Modesto (1975): De musicología asturiana. La canción tradicional, Oviedo: Instituto de Estudios Asturianos.

- (s.f.): "Eduardo Martínez Torner", en http://web.educastur.princast.es/cons/ conovied/tablon_de_anuncios/eduardomartineztorner.html (consulta el 27.02.2010).

Goyri de Menéndez-Pidal, María (19061907): "Romances que deben buscarse en la tradición oral", Revista de Archivos, Bibliotecas y Museos n. ${ }^{\circ} 10$ : 374-386, y n. ${ }^{\circ} 11:$ 24-36.

Goyri de Menéndez-Pidal, María y Eduardo Martínez Torner (1929): Romances que deben buscarse en la tradición oral, e Indicaciones prácticas para la notación musical de los romances, Madrid: Centro de Estudios Históricos.

Goyri de Menéndez-Pidal, María y Eduardo Martínez Torner (1945): Romances tradicionales y canciones narrativas existentes en el folklore español (Incipit y temas), Barcelona: Instituto Español de Musicología, CSIC.

Katz, Israel J. (2004): "A closer look at Eduardo M. Torner's Bibliographic Survey of Spain's Traditional Music and Dance", Anuario Musical, 59: 243-287.
López Sánchez, José Maria (2006): Heterodoxos Españoles. El Centro de Estudios Históricos, 1910-1936, Madrid: CSICMarcial Pons Historia.

Lorenzo Benavente, Juan Bonifacio (1991): "Eduardo Martínez Torner, del papel pautado al fotograma", en Actas del III Congreso de la A.E.H.C., San Sebastián: Filmoteca Vasca, pp. 33-50.

Mallo del Campo, María Luisa (1980): Torner, más allá del folklore, Oviedo: Universidad de Oviedo.

Mallo del Campo, María Luisa (1984): "Torner y el nuevo planteamiento científico del Folklore en España", Revista Internacional de Sociología, 51: 669-673.

Martínez Torner, Eduardo (1919): "Romance El cazador y la pastora", Asturias Gráfica, año I/2.

Martínez Torner, Eduardo (1920): Cancionero musical de la lírica popular asturiana, Oviedo: Instituto de Estudios Asturianos.

- $\quad$ (1923a): "Indicaciones prácticas sobre la notación musical de los romances", Revista de Filología Española, X/4, 389-394.

- (1923b): Colección de vihuelistas españoles. Narváez, El delphin de la música, Madrid, Junta de Ampliación de Estudios, Centro de Estudios Históricos.

- (1924a): "Del folklore español. Persistencia de algunos temas poéticos y musicales", Bulletin of Spanish Studies, 1/2, marzo, pp. 62-70.

- (1924b): "Del folklore español. Persistencia de algunos temas poéticos y musicales", Bulletin of Spanish Studies 1/3, junio, pp. 97-102.

- (1924c): Cuarenta canciones españolas, Madrid: Residencia de Estudiantes.

- $\quad$ (1925): "Ensayo de clasificación sobre las melodias de romance", Homenaje a don Ramón Menéndez Pidal, tomo II, Madrid: Hernando, 391-402.
- (1927): "Elementos populares en la poesía de Góngora", Revista de Filología, 14: 417-424.

- (1928): Cancionero Musical, Madrid: Instituto-Escuela/JAE, Biblioteca Literaria del Estudiante III.

- (1931): "La canción tradicional española musicalmente considerada", en Carreras y Candi, Folklore y costumbres de España, tomo II, 7-166.

- (1935a): Metodología del canto y de la música, Madrid: Publicaciones de la Revista de Pedagogía.

- (1935b): Temas folklóricos: música y poesía, Madrid: Faustino Fuentes.

- (1936): El folklore en la escuela, Madrid: Publicaciones de la Revista de Pedagogía.

- (1938a): Danzas valencianas (Dulzaina y tamboril). Contribución al estudio del folklore musical de la región, Barcelona.

- (1938b): "La rítmica en la música tradicional española", Revista Música, 1/1: 25-39.

- (1938c): "Música y Literatura. Tres esquemas filológicos", Revista Música, 1/3: 7-20.

- (1946): "Índice de analogías entre la lírica española antigua y la moderna", Symposium, 1/1: 12-33, noviembre.

- (1947a): "Índice de analogías entre la lírica española antigua y la moderna", Symposium 1/2: 4-35, mayo.

- (1947b): "Índice de analogías entre la lírica española antigua y la moderna", Symposium 1/3: 84-107, noviembre.

- (1948a): "Índice de analogías entre la lírica española antigua y la moderna", Symposium 2/1: 221-241, mayo.

- $\quad$ (1948b): "Índice de analogías entre la lírica española antigua y la moderna", Symposium 2/2: 221-241, noviembre. (1948c): Cancionero Musical Español, London: George Harrap. 
- (1949): "Índice de analogías entre la lírica española antigua y la moderna", Symposium 3/2: 282-320, noviembre.

- (1950): "Índice de analogías entre la lírica española antigua y la moderna", Symposium 4/1: 141-180, mayo.

- (1953): Ensayos sobre estilística literaria, Oxford: Dolphin Book Co.

- (1963): "Un aspecto de la prosa de Valle-Inclán", Grial I, 1/2: 141-180, mayo.

- (1966): Lírica hispánica: relaciones entre lo popular y lo culto, Madrid: Castalia.

Martínez Torner, Eduardo y Jesús Bal y Gay (1933): "Folklore Musical", en Terra de Mélide, Santiago de Compostela: Seminario de Estudos Galegos, 537-566 [reeditado en 1978; con una tirada aparte de 27 pp., Santiago de Compostela: Nós].

- (1973/2007): Cancionero Gallego, A Coruña: Fundación Barrié de la Maza.

Menéndez Pidal, Ramón (1910): El Romancero español, Nueva York: The Hispanic Society of America.

- (1928/1933): Flor nueva de romances viejos, 2. edición corregida y aumentada, Madrid: Revista de Archivos, Bibliotecas y Museos.

- (1953): Romancero Hispánico, Madrid: Espasa-Calpe.

Pliego de Andrés, Víctor (2006): "El Servicio de Música: Eduardo Martínez
Torner y Pablo de Andrés Cobos", catálogo de la exposición Las Misiones Pedagógicas, 1931-1936, Madrid: Sociedad Estatal de Conmemoraciones Culturales y Residencia de Estudiantes, 414-443.

Prat Ferrer, Juan José (2008): Bajo el árbol del paraíso. Historia de los estudios sobre el folklore y sus paradigmas, Madrid: CSIC-IE Universidad.

Presas, Adela (2003-2004): "La Residencia de Estudiantes (1910-1936): actividades musicales", Música: Revista del Real Conservatorio Superior de Música de Madrid, 10-11, 55-104.

Querol Gavaldá, Miguel (1971/1989): Cancionero musical de la Colombina, Madrid: Sociedad Española de Musicología.

- (1975): Cancionero musical de Góngora, Barcelona: Instituto Español de Musicología-CSIC.

- (1989): Cancionero musical de Turín: transcripción y estudio, Barcelona: Instituto Español de MusicologíaCSIC.

Ribera y Tarragó, Julián (1922): La música de las "Cantigas": estudio sobre su origen y naturaleza, Madrid: Tipología de la Revista de Archivos.

- (1925): "De música y métrica gallegas", Homenaje a don Ramón Menéndez Pidal, tomo III, Madrid: Hernando, 7-35.
- (1927): La música árabe y su influencia en la música española, Madrid: Editorial Voluntad.

- (1928): La música de la Jota aragonesa, Madrid: Instituto de Valencia de Don Juan.

Sánchez de Andrés, Leticia (2006): "La música en la Junta para Ampliación de Estudios: la política de concesión de pensiones y el Centro de Estudios Históricos", Boletín de la ILE 63-64: 229-248.

Schindler, Kurt (1941): Folk Music and Poetry of Spain and Portugal, New York, NY: Hispanic Institute.

Seris, Homero (1966): "Prólogo", en E. Martínez Torner, Lírica Hispánica (relaciones entre lo popular y lo culto), Madrid: Editorial Castalia, pp. 7-11.

Trend, John B. (1929): "The Mystery of the Sybil Cassandra", Music \& Letters 10/2: 124 (abril).

Valverde, Alfredo (1998): "Centro de Documentación: el Archivo de la Palabra y las canciones populares", Revista Residencia, 6: s. p. (julio-agosto).

Villanueva, Carlos (2007): "El cancionero que fue y el que pudo haber sido", en Cancionero Gallego de Eduardo Martínez Torner \& Jesús Bal y Gay, A Coruña: Fundación Barrié de la Maza.

Villanueva, Carlos, ed. (2006): Jesús Bal y Gay. Tientos y silencios 1905-1993, Catálogo de la exposición homónima. Madrid: Residencia de Estudiantes. 